\title{
Investigation on Current Control Defrosting Method of Multi-split Variable Refrigerant Flow System
}

\author{
Min Liu ${ }^{1}$, Hexin Liu ${ }^{2}$, Meng Wang ${ }^{3 *}$, Hua Chen ${ }^{4}$ \\ Key Laboratory of AUX Air Conditioning Co., Ltd, Ningbo, Zhejiang, 315191, (China) \\ E-mail: ${ }^{1}$ liumin28@ mail.aux-home.com, ${ }^{2}$ liuhexin@ mail.aux-home.com, ${ }^{3}$ wangmeng155@126.com ${ }^{4}$ chenhua4@ mail.aux- \\ home.com
}

Received 1 July 2020, Revised 6 August 2020, Accepted 1 October 2020

\begin{abstract}
There are many indoor units in the multi-split variable refrigerant flow (VRF) system. The continuous operation of heating in winter is longer than that of ordinary household air conditioning, so that the precise defrosting control is energy-saving and improves the comfort for users. In this paper, during the experiment, the indoor temperature was $20^{\circ} \mathrm{C}$, the outdoor dry bulb temperature was $7^{\circ} \mathrm{C}, 0^{\circ} \mathrm{C},-5^{\circ} \mathrm{C}$ and $-7^{\circ} \mathrm{C}$, and the wet bulb temperature was $6^{\circ} \mathrm{C}, 0^{\circ} \mathrm{C},-6$ ${ }^{\circ} \mathrm{C}$ and $-8^{\circ} \mathrm{C}$ respectively. The defrosting temperature, liquid pipe temperature, defrosting time and the current value change rate of the condenser fan were compared when the heating capacity was reduced by $15 \%$. The experiments showed that the current change rate was only related to the frost mass rather than the outdoor temperature. The best fan current change rate was $15 \%-20 \%$ when to defrost for the VRF system. Compared with the traditional defrosting, the phenomenon of thermosensor falling off and the uneven frost formation had little impact on the current control defrosting.
\end{abstract}

Keywords: VRF; defrosting; current control; optimization.

\section{Introduction}

During heating operation of air conditioning system in winter, the condenser is placed outside. The heat exchanger will frost, when the surface temperature is lower than the dew point temperature and lower than $0^{\circ} \mathrm{C}$. In the early frosting stage of the condenser, the frost layer on the surface of the condenser has the effect of enhancing heat transfer [1]. However, with the continuous thickening of the frost layer, the heat transfer resistance between the condenser surface and the surrounding environment will increase. The frost layer will block the air flow between the fin pipes, resulting in the deterioration of the heat transfer performance of the condenser. The $\mathrm{COP}$ of the system will be reduced [2]. In order to ensure the stability of heating operation, the condenser needs to be defrosted periodically [3]. The multi-split variable refrigerant flow (VRF) system was first proposed by the air conditioning experts in Japan. It is easy to install and can be selected according to the users' needs. It is suitable for different room types [4]. At the same time, the multi-split VRF system has high energy efficiency and meets the energy saving requirements [5]. Therefore, it is widely used in office buildings, villas and residential buildings. There are many indoor units in the multi-split VRF system and the heating demand is large. The continuous operation of heating in winter is longer than that of ordinary household air conditioning [6, 7]. Therefore, when to start defrosting needs higher control requirements.

There are many common ways about the entry conditions of defrosting control. The timing control defrosting method [8] controls when to defrost by time, which is simple and easy to achieve. However, it does not consider the impact of environmental temperature changes, so it is easy to conduct false defrosting. Later, the above methods have been modified, and the timing-temperature control defrosting method [9] has been proposed, which is also the most commonly used defrosting control method at present. In this method, an evaporation temperature parameter or superheat parameter is added to the timing control defrosting method. When any condition of time or temperature is satisfied, defrosting begins. The cost of this control method is low, and the defrosting effect is good. However, it is hard and subjective to select the temperature and superheat. The self-adaptive control defrosting method [10] can automatically determine the defrosting time according to the actual situation. Its detection parameters are comprehensive, which can reduce the false defrosting to the greatest extent. However, its control is relatively complex, and it cannot accurately determine the functional relationship of many parameters, which has a strong subjectivity and empiricism.

Air pressure difference defrosting control method [11] measures the pressure value on both sides of the heat exchanger. The pressure drops on both sides of the heat exchanger increase when the frost layer increases. When to defrost can be judged by the change of pressure difference. In the photoelectric sensor control defrosting method [12, 13], a photoelectric sensor unit composed of transmitter and collector is installed at the front of the heat exchanger to accurately monitor the frost layer temperature thickness. The control cost of these two methods is high and the stability of control accuracy is poor. In addition, there are maximum average heat supply control method [14, 15], ultrasonic control defrosting [16], heat conduction and radiation control defrosting [17], effective mass flow fraction control method [18], refrigerant flow control method [19], etc. The above defrosting control methods have their own advantages and disadvantages, which are suitable for different refrigeration systems and control occasions with different precision requirements. 
It is an important part for enterprises and scholars to improve the accurate judgment of defrosting time of multisplit VRF system. Early access to defrosting will make defrosting too frequent, which will affect the users' experience. The reason is that defrosting will change the system to the cooling mode. Access to defrosting too late will make the frost layer too thick. The heating effect will be poor and the power consumption will increase. Therefore, the research applied the current control defrosting method to the VRF system. The best fan current change rate was put forward through the physical model and the comparative experiment.

\section{Current Control Defrosting Principle}

For the determination of the start time of defrosting, if it was determined according to the pipe temperature and pressure value, it belonged to indirect judgment, and there was a large error. According to the current value of the fan, it could directly reflect the real situation of frosting. With the increase of frosting and wind resistance, the fan motor needs more torque to provide the same heating capacity. The heating capacity and capacity attenuation rate were shown in Eqs. (1)-(3). According to the Eq. (5), when the speed and the motor constant were unchanging, the torque of the motor was increased and the effective power of the motor was also increased. Similarly, according to Eq. (6), when the frost amount was increased, the air volume was decreased. In order to get the same heat exchange and increase the volume flow, the effective power of the motor must be increased. According to the Eqs. (7)-(9), the input power of the prime mover was also increased. According to Eq. (10), when the input voltage of the motor was fixed, the greater the input power of the prime mover was, the greater the current value was. Therefore, the frost degree of outdoor heat exchanger could be determined according to the current value.

Under the heating condition, the heating capacity and capacity decay rate were shown in Eqs. (1)-(3).

$$
\begin{aligned}
& Q=q_{m t} C_{p a}\left(t_{a 2}-t_{a 1}\right) /\left[V_{n}\left(1+W_{n}\right)\right] \\
& C_{p a}=1006+1860 \mathrm{~W}
\end{aligned}
$$

$$
\eta=\frac{W_{\max }-W}{W_{\max }} \times 100 \%
$$

Where, $Q$ was heating capacity, W; $q_{m t}$ was indoor air flow measurement value, $\mathrm{m}^{3} / \mathrm{s} ; C_{p a}$ was specific heat at constant pressure on air side, $\mathrm{J} /(\mathrm{kg} \cdot \mathrm{K}) ; t_{a 1}$ was dry bulb temperature of air entering the indoor, ${ }^{\circ} \mathrm{C} ; t_{a 2}$ was dry bulb temperature of air leaving the indoor, ${ }^{\circ} \mathrm{C} ; V_{n}$ was specific enthalpy of air at nozzle, $\mathrm{m}^{3} / \mathrm{kg} ; W_{n}$ was moisture content of air at nozzle, $\mathrm{kg} / \mathrm{kg} ; W$ was moisture content of air entering the indoor, $\mathrm{kg} / \mathrm{kg} ; \eta$ was capacity decay rate; $Q_{\max }$ was heating capacity after defrosting, W.

The calculation of heating performance coefficient was shown in Eq. (4).

$$
\mathrm{COP}=\frac{Q}{W}
$$

Where, COP was coefficient of heating performance; $Q$ was heating capacity, $\mathrm{W} ; W$ was power consumed, $\mathrm{W}$.

The power analysis of condenser fan was shown in Eqs. (5)-(9).

$P_{e}=M n \cdot \mathrm{K}$

Where, $P_{e}$ was fan effective power, $\mathrm{W} ; M$ was motor torque, $\mathrm{N} \cdot \mathrm{m} ; n$ was fan rotation speed, $\mathrm{r} / \mathrm{min}$; $\mathrm{K}$ was motor constant (Related to motor type).

$$
P_{e}=q_{v} P_{a}
$$

$P_{e}=\eta P$

$$
P=\eta_{t m} P_{g}
$$

$$
P_{g}=k \eta_{g} P_{g, i n}
$$

Where, $q_{v}$ was volume flow, $\mathrm{m}^{3} / \mathrm{s} ; P_{a}$ as total pressure, $\mathrm{P}_{\mathrm{a}} ; \eta$ was fan efficiency; $P$ was shaft power (input power), $\mathrm{W} ; \eta_{t m}$ was mechanical transmission efficiency; $P_{g}$ was prime mover power, $\mathrm{W} ; k$ was capacity safety factor; $\eta_{g}$ was prime mover efficiency; $P_{g \text {,in }}$ was prime mover input power, W.

$$
P_{g, i n}=U I
$$

Where, $U$ was motor input voltage, $\mathrm{V} ; I$ was motor input electric current, A.

Dimensionless number of electric current change rate was shown in Eq. (11).

$$
\eta_{I}=\frac{I_{s}-I_{e}}{I_{s}} \times 100 \%
$$

Where, $\eta_{I}$ was electric current change rate; $I_{s}$ was fan current value without frost, $\mathrm{A} ; I_{e}$ was fan current value starting defrosting, A.

\section{Experimental Setup \\ 3.1. Multi-split VRF System}

The multi-split VRF system adopted the mode of 'one driving three' (one outdoor unit ran with three indoor units), as shown in Figure 1. In the heating mode, the exhaust gas of compressor B was firstly fed into oil separator $\mathrm{C}$. Then, it entered into the starting indoor units $\mathrm{Y}$ through four-way reversing valve $D$. After that the refrigerant entered to the outdoor heat exchanger $G$ for evaporation and heat absorption. Then it entered to the gasliquid separator A, Finally, the refrigerant returned to compressor B. The branch where the capillary $\mathbf{J}$ and filter $\mathrm{S}$ located was the oil return pipe, which was used for the oil return of the compressor. The branch of capillary $\mathbf{J}$ and solenoid valve I was air bypass, which made the compressor start smoothly and prevented danger due to high pressure. The parameters of the system devices were detailed in Table 1. It is worth noting that the condenser fan used in the experiment was a brushless DC motor. The power was $170 \mathrm{~W}$ and the speed was 740r / min. 


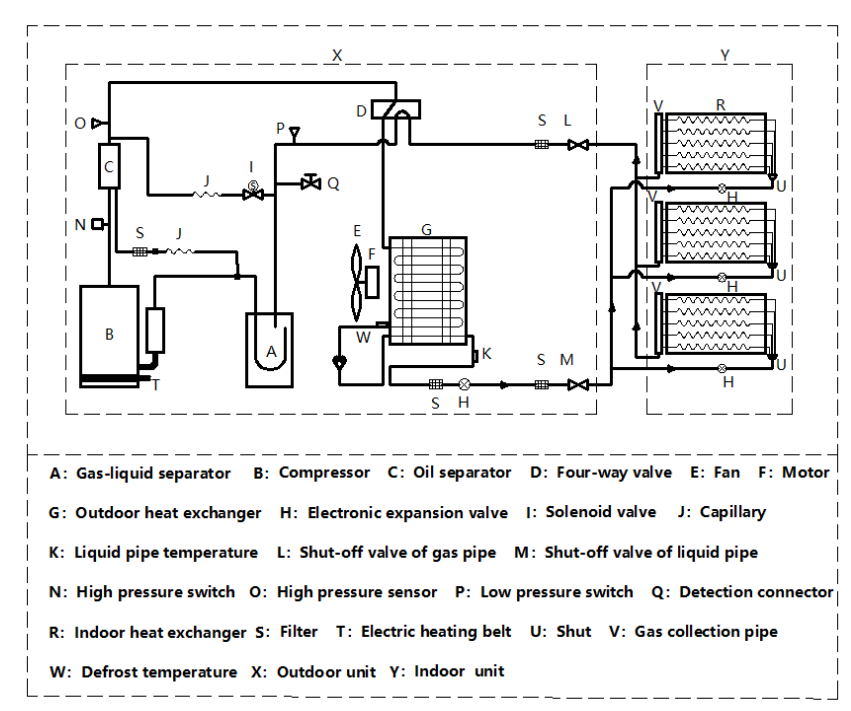

Figure 1. Schematic diagram of multi-split VRF system.

Table 1. Specifications of the device.

\begin{tabular}{ccc}
\hline Item & Parameter & Value \\
\hline Compressor & Type & Rotary compressor \\
& Displacement & $30.8 \mathrm{~m} 3 / \mathrm{h}$ \\
Condenser & Type & Air cooled condenser \\
& Fin spacing & $1.6 \mathrm{~mm}$ \\
& Pipe diameter & $7 \mathrm{~mm}$ \\
Fan motor & Type & Brushless DC motor \\
& Model & ZWB4710L07A \\
& Power & $170 \mathrm{~W}$ \\
Gas-liquid & Rotation rate & $740 \mathrm{r} / \mathrm{min}$ \\
separator & Volume & $4.6 \mathrm{~L}$ \\
Oil separator & Volume & $0.20 \mathrm{~L}$ \\
& Type & Mesh \\
Solenoid valve & Type & FDF2A95 \\
& Valve & $3.6 \mathrm{MPa}$ \\
& differential & \\
pressure & \\
Electronic & Type & UKV-32D61 \\
valve*4 & Control & \\
& accuracy & $0 \sim 480 \mathrm{pls}$ \\
& Valve & $3.5 \mathrm{MPa}$ \\
& differential & \\
Pressure switch & pressure & Type \\
Four-way valve & Type & YK-4.2/3.3 \\
& Internal leakage & $\leq 1500 \mathrm{ml} / \mathrm{min}$ \\
Pressure sensor & Type & $35 \mathrm{CP} 02$ \\
& Pressure range & $0 \sim 5 \mathrm{MPa}$ \\
\hline
\end{tabular}

There were two temperature measuring points and two pressure measuring points arranged in the experimental system, and the arrangement position was shown in Figure 1 . The two temperature measuring points were the liquid pipe temperature $\mathrm{K}$ and defrost temperature $\mathrm{W}$. T-type thermocouple was used for temperature measurement. The measurement range was $-50 \sim 150^{\circ} \mathrm{C}$, and the measurement error was $\pm 0.5^{\circ} \mathrm{C}$. The two pressure measuring points were high pressure sensor $\mathrm{O}$ and low pressure sensor $\mathrm{P}$ respectively. The pressure sensor of $35 \mathrm{CP} 02$ was selected for pressure measurement. The measurement range was $0 \sim 5 \mathrm{MPa}$ and measurement error was $\pm 0.01 \mathrm{MPa}$.

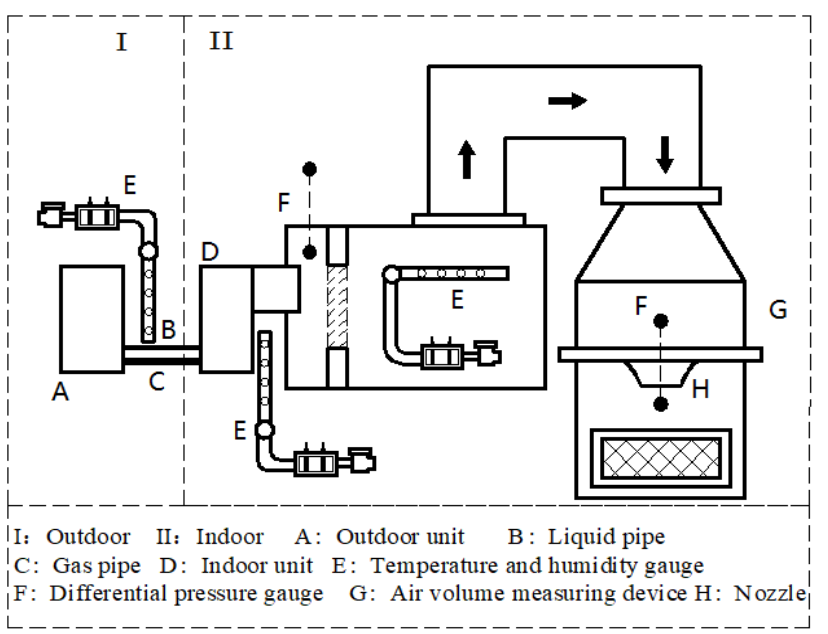

Figure 2. Schematic diagram of the air enthalpy method calorimeter.

\subsection{Test Laboratory System}

The air enthalpy method calorimeter was divided into two parts: Indoor I and Outdoor II. Temperature and humidity regulation were adopted to regulate the temperature of air dry and wet bulb, that is, the air conditioning system continued to operate to cool down and dehumidify. By controlling the power output of heater and humidifier, the temperature control device of dry and wet bulb could adjust the heat and moisture in the air, so as to obtain the required air temperature and humidity. The air sampling device was used to measure the air supply temperature and air return temperature of the air conditioning, mainly including: sampling pipe, sampling fan, sampling table and wet bulb make-up cup. The installation position was shown in Figure 2. It could also be measured directly in enough positions, and then its average temperature could be determined. The temperature sampling and testing device of air return outlet shall be located $0.15 \mathrm{~m}$ away from the air return outlet of air conditioning. Finally, the heating capacity of the air conditioning was determined by measuring the air dry and wet bulb temperature and air flow at the inlet and outlet of the air conditioning.

\subsection{Experimental Method}

Three indoor air conditionings were placed on the indoor side of the air enthalpy method calorimeter, and the outdoor air conditioning was placed on the outdoor side of the air enthalpy method calorimeter. The indoor temperature was $20^{\circ} \mathrm{C}$, the outdoor dry bulb temperature is set to $7^{\circ} \mathrm{C}, 0^{\circ} \mathrm{C},-5^{\circ} \mathrm{C}$ and $-7^{\circ} \mathrm{C}$, and the wet bulb temperature is set to $6^{\circ} \mathrm{C}, 0^{\circ} \mathrm{C},-6^{\circ} \mathrm{C}$ and $-8^{\circ} \mathrm{C}$, respectively. Experiment 1: The natural frosting experiments under different outdoor temperatures were carried out, and the current value of the condenser fan, defrosting temperature, liquid pipe temperature, operation time, air supply temperature and capacity value were recorded at this time. Experiment 2: The natural frosting experiments under different outdoor temperatures were carried out. The manual defrosting was started when the current change rates were $5 \%, 10 \%, 15 \%, 20 \%, 25 \%$ and $30 \%$ respectively, and ran a complete defrosting cycle. The capacity change values were recorded at this time. Experiment 3: The traditional defrosting and current control defrosting were used to defrost. The heating cycle capacity under four working conditions was recorded. Experiment 4: Under the 
condition of thermosensor falling off and the uneven frost formation, the traditional defrosting and current control defrosting were used for defrosting experiment. The operation time, heating cycle capacity, air supply temperature and capacity decay rate of the two situations were recorded.

\section{Results and Discussion}

\subsection{Characteristics Analysis of Current Contro Defrosting}

At present, three most widely used defrosting methods in the field of air conditioning are defrosting temperature judgment (Defrosting temperature refers to the temperature of the liquid pipe at the bottom of the condenser flow path. Due to the distribution of the wind field, the heat exchange effect of the bottom path is poor and frosting is the worst. Therefore, the temperature of the bottom path is used as defrosting temperature), liquid pipe temperature judgment and operation time judgment. For the air conditioning industry, $15 \%$ reduction of heating capacity affects the heating effect of the system [20]. The decay rate of heating capacity was calculated by Eq. (1). Under the conditions of $7^{\circ} \mathrm{C}, 0^{\circ} \mathrm{C},-5^{\circ} \mathrm{C}$ and $-7^{\circ} \mathrm{C}$ respectively, when the heating capacity decreased by $15 \%$, the values of the four criteria were shown in Table 2. It can be seen from the Table 2 that the defrosting temperature was gradually decreased with the decrease of the outdoor temperature. The outdoor dry bulb temperature was decreased from $7^{\circ} \mathrm{C}$ to $0^{\circ} \mathrm{C}$, and the defrosting temperature was decreased from $-3^{\circ} \mathrm{C}$ to $-10.6^{\circ} \mathrm{C}$ correspondingly. The defrosting temperature changed $7.6^{\circ} \mathrm{C}$. The outdoor dry bulb temperature was decreased from $0^{\circ} \mathrm{C}$ to $-7^{\circ} \mathrm{C}$, the defrosting temperature was decreased from $-10.6^{\circ} \mathrm{C}$ to $-14.5^{\circ} \mathrm{C}$ correspondingly. The defrosting temperature changed $3.9^{\circ} \mathrm{C}$. The difference of the defrosting temperature change was due to the high outdoor temperature. The temperature difference of heat transfer was large, so that the defrosting temperature change was large. Therefore, the defrosting temperature was greatly affected by the outdoor temperature, and the relationship between the outdoor temperature and defrosting temperature was not linear. It is necessary to determine the defrosting temperature under different outdoor temperature through experiments. The setting is complex, subjectivity and empiricism. Similarly, the liquid pipe temperature was gradually decreased with the decrease of the external environment temperature, and the change rule was the same as the defrosting temperature. The only difference is that the defrosting temperature tested the area with the most serious frosting, while the liquid pipe temperature detected the impact of the total amount of frosting.

Timing control defrosting is the simplest control method. However, it can also be seen from Table 2 that when the heating capacity was decayed by $15 \%$, the operation time of the four working conditions were different. Therefore, it was difficult to achieve accurate defrosting. The capacity decay rate could be calculated according to Eqs. (1)-(3). It was the easiest conditions to frost when the outdoor temperature was $0^{\circ} \mathrm{C}$, and the operation time was only 33 minutes. This is because the temperature of $0^{\circ} \mathrm{C}$ reached the frost condition, and the relative humidity in the air was much. It was easy to frost. While the outdoor temperature was $-15^{\circ} \mathrm{C}$, it was difficult to frost because of the low humidity. It was hard to judge the frost mass by time. Compared with defrosting temperature, liquid pipe temperature and operation time, under different outdoor temperatures, when the heating capacity decayed by $15 \%$, the current change rate of condenser fan was about $17 \%$ (the current change rate was calculated by Eq. (11)), which changed little with the outdoor temperature. Therefore, taking the current change rate of condenser fan as the start sign of defrosting, accurate defrosting could be realized, which was less affected by the change of outdoor temperature.

The curve in Figure 3 showed that the current value of condenser fan changed with the time when the outdoor temperature was $7^{\circ} \mathrm{C}$. After the multi-split VRF system ran, the current was increased rapidly, such as OA section. The current value was increased rapidly from $0 \mathrm{~A}$ to $1.4 \mathrm{~A}$. Under the condition of no frosting, such as section $\mathrm{AB}$, the current of condenser motor kept $1.4 \mathrm{~A}$ all the time. With the increase of the frost layer on the condenser surface, according to Eqs. (4)-(8), the volume of the wind was decreased. In order to achieve the same heat exchange, it was necessary to increase the effective power of the fan, so as to increase the power of the prime mover. Under the condition of constant voltage, the current value was increased gradually, as shown in section BC. With the continuous increase of the frost, the current changed tend to be stable (1.9A), such as CD section, and the current change rate was $35.7 \%$. This is because the frost growth is the formation of frost cores first, then the growth of frost branches and leaves. After the frosting condition is reached, the frost core will be formed on the surface of the heat exchanger first. The frost core has a great influence on the heat exchanger, which will result in an obvious increase of wind resistance, resulting in an obvious change of current value. However, when the frost core is formed, the frost will grow on the frost core in the shape of branches and leaves. This kind of frost is fluffy, which has no obvious blocking effect on the heat exchanger. The change of wind resistance is small, resulting in basically the same current value

Table 2. Values of four defrosting indexes at different outdoor temperatures.

\begin{tabular}{cccccc}
\hline $\begin{array}{c}\text { Outdoor dry } \\
\text { bulb } \\
\text { temperature }\end{array}$ & $\begin{array}{c}\text { Outdoor wet } \\
\text { bulb } \\
\text { temperature }\end{array}$ & $\begin{array}{c}\text { Current } \\
\text { change rate }\end{array}$ & $\begin{array}{c}\text { Defrosting } \\
\text { temperature }\end{array}$ & $\begin{array}{c}\text { Liquid pipe } \\
\text { temperature }\end{array}$ & Operation time \\
\hline $7^{\circ} \mathrm{C}$ & $6^{\circ} \mathrm{C}$ & $16.6 \%$ & $-3^{\circ} \mathrm{C}$ & $-10^{\circ} \mathrm{C}$ & $101 \mathrm{~min}$ \\
$0^{\circ} \mathrm{C}$ & $0^{\circ} \mathrm{C}$ & $17.2 \%$ & $-10.6^{\circ} \mathrm{C}$ & $-18^{\circ} \mathrm{C}$ & $33 \mathrm{~min}$ \\
$-5^{\circ} \mathrm{C}$ & $-6^{\circ} \mathrm{C}$ & $17.5 \%$ & $-13.7^{\circ} \mathrm{C}$ & $-21.5^{\circ} \mathrm{C}$ & $74 \mathrm{~min}$ \\
$-7^{\circ} \mathrm{C}$ & $-8^{\circ} \mathrm{C}$ & $18.1 \%$ & $-14.5^{\circ} \mathrm{C}$ & $-22^{\circ} \mathrm{C}$ & $73 \mathrm{~min}$ \\
\hline
\end{tabular}




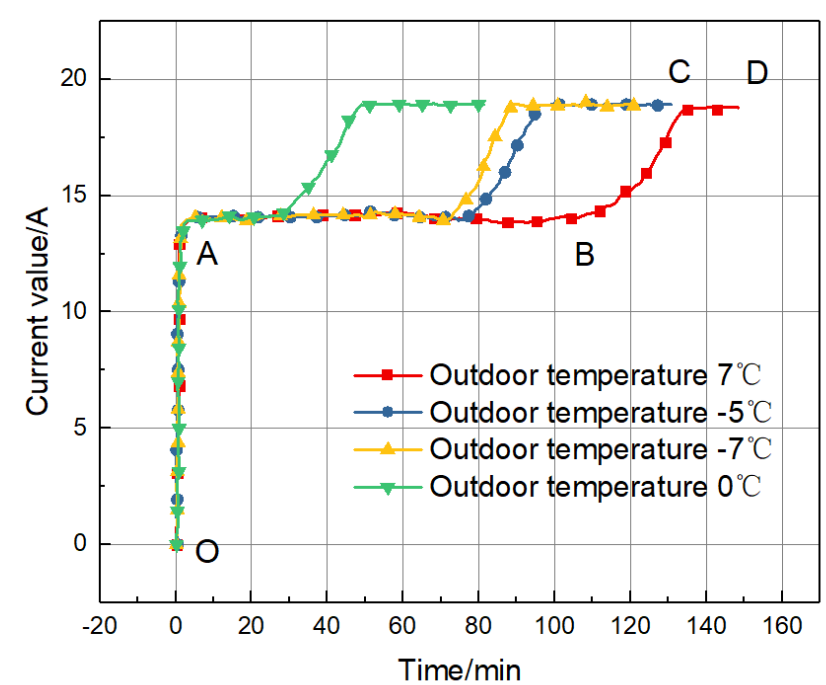

Figure 3. The current value of condenser fan changed with time under different outdoor temperature.

As shown in Figure 3, for the same of fan power, when the outdoor temperature was $7{ }^{\circ} \mathrm{C}, 0{ }^{\circ} \mathrm{C},-5{ }^{\circ} \mathrm{C}$ and $-7{ }^{\circ} \mathrm{C}$ respectively, the trend of the current value of the condenser fan with time was exactly the same. The $\mathrm{AB}$ section was $1.4 \mathrm{~A}$ all the time, but the length was different. This is due to the different degree of frosting under different working conditions, resulting in different stable operation time. However, it was enough to show that the current value of condenser fan was not affected by the outdoor temperature, and it was a sign that directly reflected the frosting of heat exchanger. Therefore, the time of defrosting could be determined according to the current change rate. Next, the paper will discuss how to choose the appropriate current change rate.

\subsection{Judgment Method of Current Control Defrosting (1) Heating Cycle Capacity Judgment}

Heating cycle capacity refers to the average heating capacity from the end of the previous defrosting cycle to the end of the next defrosting cycle. As shown in Figure 4, the heating capacity changed with time under the condition that the outdoor temperature was $0{ }^{\circ} \mathrm{C}$ and the indoor temperature was $20^{\circ} \mathrm{C}$. Point $\mathrm{A}$ was the end of the last defrosting cycle. For AB section, the compressor started-up and entered to the heating mode again. The heating capacity was gradually increased. The outdoor temperature was $0^{\circ} \mathrm{C}$, which was the easiest frost working condition, and began to frost vary soon. In the early stage of frosting, the heating capacity had a small increase, as shown in section BC. The reason is that when there was less frosting, the heat transfer efficiency was enhanced compared with the rib efficiency. However, with the increase of frost layer, the heat transfer resistance was increased, and the heating capacity was gradually decreased as shown in the CD section. The defrosting stage started at point $\mathrm{D}$, and the heating capacity was decreased rapidly at DE section. Even the heating capacity was negative value sometimes. This is because the defrosting method was reverse defrosting, and the system changed from heating mode to refrigeration mode. Therefore, it is necessary to control the time and frequency of defrosting. The accurate control of defrosting could improve the overall performance of the system. The end point of defrosting was point $\mathrm{E}$, so from point $\mathrm{A}$ to $\mathrm{E}$ was a complete heating cycle. The average value of its capacity was the heating cycle capacity.

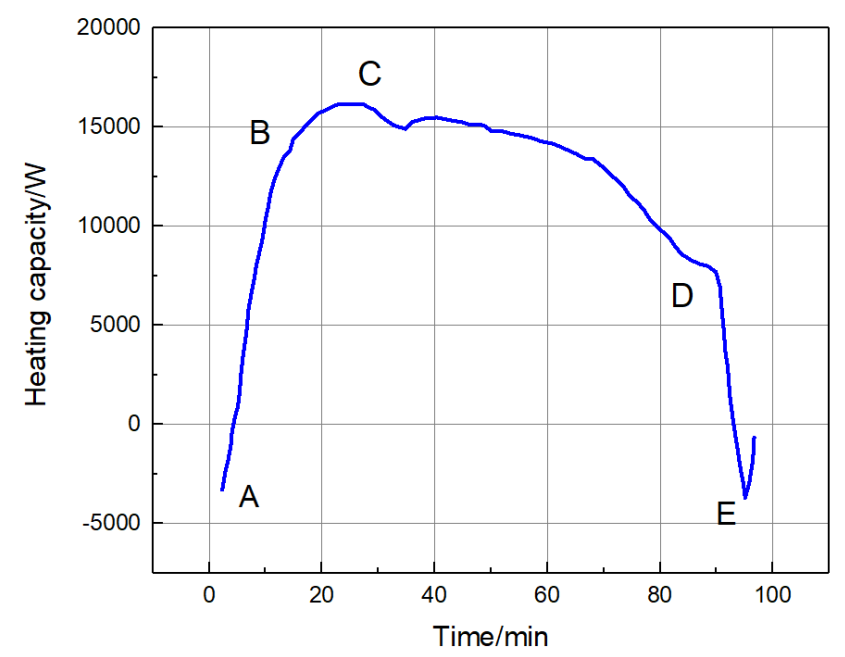

Figure 4. The relationship between heating capacity and time.

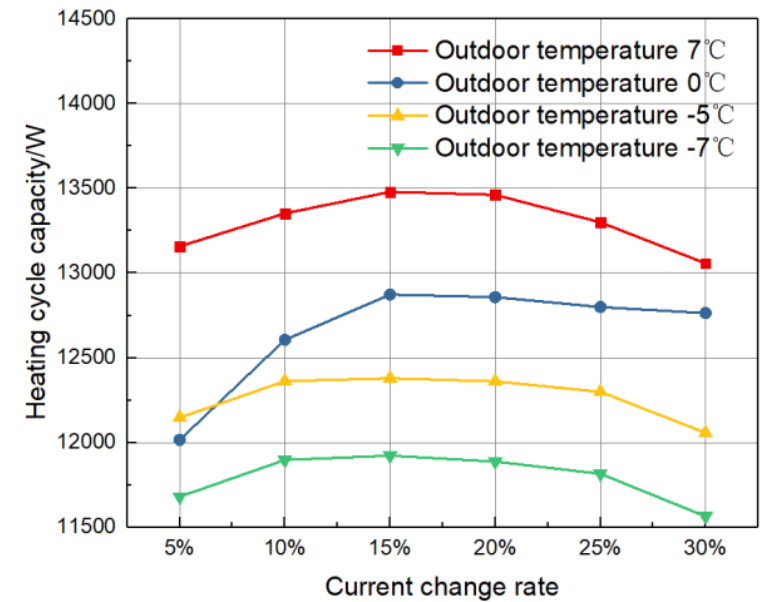

Figure 5. Heating cycle capacity changed with different current change rate at different outdoor temperatures.

In order to select the appropriate current change rate of condenser fan as the judgment mark of defrosting start, it could be judged by the heating cycle capacity. As shown in Figure 5, the corresponding heating cycle capacity was obtained when selecting different condenser fan current change rate for defrosting under different outdoor temperature. The heating cycle capacity was increased first and then decreased with the increase of current change rate of condenser fan when the outdoor temperature was $-7^{\circ} \mathrm{C}$, $5^{\circ} \mathrm{C}, 0{ }^{\circ} \mathrm{C}$ and $7^{\circ} \mathrm{C}$. This is because the defrosting started when the current change rate was too low, which leaded to the frequent defrosting. The defrosting time accounted for a large proportion. The heating cycle capacity was low. If the defrosting started when the current change rate was too high, the capacity decay rate was high and heating cycle capacity was low in the heating process. Therefore, there was an optimal heating cycle capacity and the corresponding current change rate was $15 \%$. When the outdoor temperature was $-7^{\circ} \mathrm{C},-5^{\circ} \mathrm{C}, 0{ }^{\circ} \mathrm{C}$ and $7{ }^{\circ} \mathrm{C}$, the corresponding cycle capacity was $11922.6 \mathrm{~W}, 12379.5 \mathrm{~W}$, $12873.1 \mathrm{~W}$ and $13479.5 \mathrm{~W}$ respectively. Figure 5 also showed that when the current change rate was fixed, the heating cycle capacity was increased with the increase of 
outdoor temperature. The reason is that the outdoor temperature was increased, which leaded to the evaporation temperature increased. Therefore, the power consumption was decreased. According to the Eq. (4), the capacity was increased. However, when the current change rate was $5 \%$ and the outdoor temperature was $0^{\circ} \mathrm{C}$, the heating cycle capacity was $12016.2 \mathrm{~W}$. It was lower than the $-5^{\circ} \mathrm{C}$, which was $12147.9 \mathrm{~W}$. The reason was that when the outdoor temperature was $0{ }^{\circ} \mathrm{C}$, it was the most easily frosting condition. Defrosting was carried out at $5 \%$, resulting in the proportion of defrosting time in the whole heating cycle was higher than that at $-5^{\circ} \mathrm{C}$.

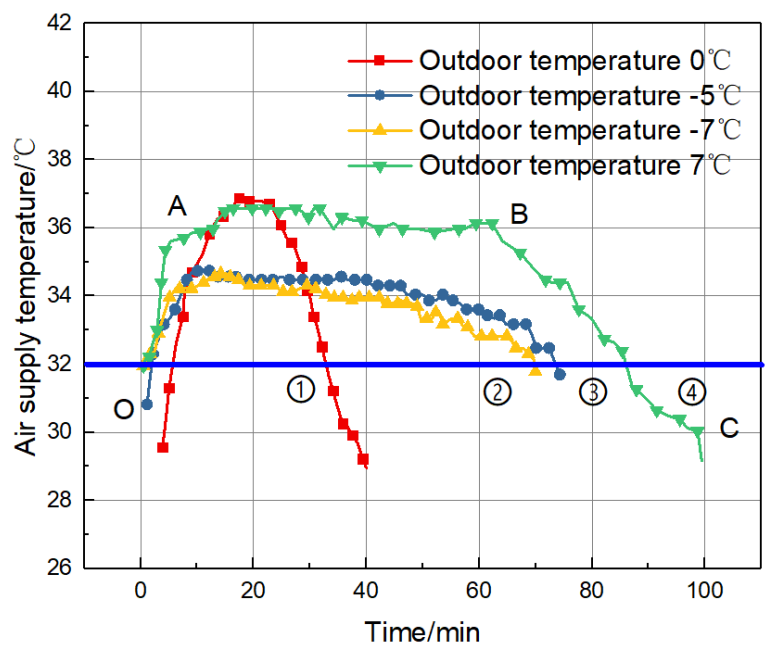

Figure 6. The relationship between the air supply temperature of the internal air conditioning and time under different outdoor temperatures

\section{(2) Air Supply Temperature Judgement}

According to the air supply temperature judgment, the appropriate defrosting current change rate could also be selected. As shown in Figure 6, the air supply temperature of the indoor air conditioning changed with time, when the indoor temperature was $20^{\circ} \mathrm{C}$ and the outdoor temperature was $7^{\circ} \mathrm{C}, 0^{\circ} \mathrm{C},-5^{\circ} \mathrm{C}$ and $-7^{\circ} \mathrm{C}$ respectively. OA section was the start-up stage of the compressor, and the air supply temperature of the indoor air conditioning was increased gradually. Section AB was the air supply temperature during normal operation. The higher the outdoor temperature was, the higher the air supply temperature of the indoor air conditioning was. The reason is that in the heating condition, the higher the outdoor temperature was, the higher the evaporation temperature was. For the same frequency, the higher the condensation temperature was, the higher the air supply temperature was. From point B, the heat exchanger of the condenser began to frost. As the frosting progressing, the air volume was decreased, which leaded to the evaporation temperature and the condensation temperature were decreased. Therefore, the air supply temperature was decreased, as shown in section BC. In order to ensure the comfort of the human body and the rapid temperature rise of the indoor temperature, the air supply temperature shall not be lower than $32{ }^{\circ} \mathrm{C}$ [21]. Therefore, the corresponding fan current change rate could be selected as the starting condition of defrosting when the air supply temperature was $32^{\circ} \mathrm{C}$. As shown in Fig. 6, for four different outdoor temperatures, when the air supply temperature was $32^{\circ} \mathrm{C}$, the corresponding current change rates of (1), (2), (3) and (4) were 20\%, 15\%, $18 \%$ and $19 \%$. Therefore, it was better to start defrosting when the current change rate was $15 \%-20 \%$.

\section{(3) Heating Capacity Decay Rate Judgement}

As shown in Figure 7, the heating capacity decay rate corresponded to different current change rates when the outdoor temperature was $7^{\circ} \mathrm{C}, 0^{\circ} \mathrm{C}, 5^{\circ} \mathrm{C}$ and $-7^{\circ} \mathrm{C}$. It could be seen from the change trend of the four curves that the current change rate was increased gradually, and the heating capacity decay rate was also increased gradually. The direct reason for the increase of current change rate was the increase of frost mass, which affected the heat exchange of outdoor unit and leaded to the increase of heating capacity decay. When the current change rate was $5 \%$, the heating capacity decay rate under the four working conditions were $2.87 \%, 3.06 \%, 3.6 \%$ and $4.21 \%$ respectively, which had a relatively small impact on the heating capacity. If the defrosting was started at this time, it was too frequent and affected the user experience. However, when the current change rate was $30 \%$, the heating capacity decay rate under the four working conditions were $30.84 \%$, $32.45 \%, 38.19 \%$ and $39.45 \%$, which seriously affected the heating capacity and increased power consumption. Therefore, the appropriate defrosting current change rate could be selected through the heat capacity decay rate. When the heating capacity was decayed by $15 \%$, the current change rate was $16.6 \%, 17.2 \%, 17.5 \%$ and $18.1 \%$, respectively. The current change rate was between $15 \%$ and $20 \%$. Therefore, it was better to start defrosting when the current change rate was $15 \%-20 \%$. It is worth noting that the higher the outdoor temperature was, the lower the heating capacity decay rate was. This is because the higher the outdoor temperature was, the higher the heating capacity was before frosting. Therefore, the performance effect of frosting was smaller.

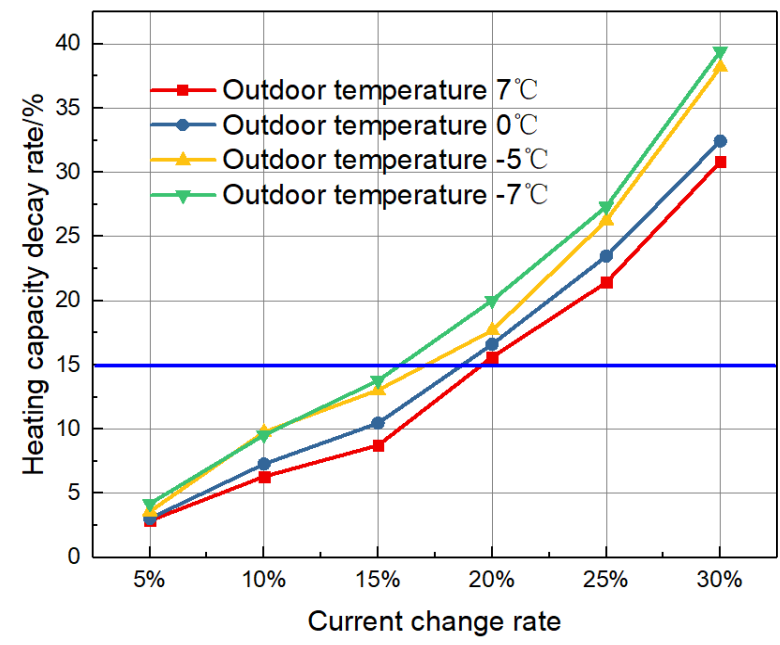

Figure 7. The relationship between the heating capacity decay rate and current change rate under different outdoor temperature.

Considering the above three methods of selecting current change rate, it was the best to start defrosting when the current change rate of condenser fan was $15 \%-20 \%$. The same was true for the real experimental observations. As shown in Figure 8, when the outdoor temperature was 

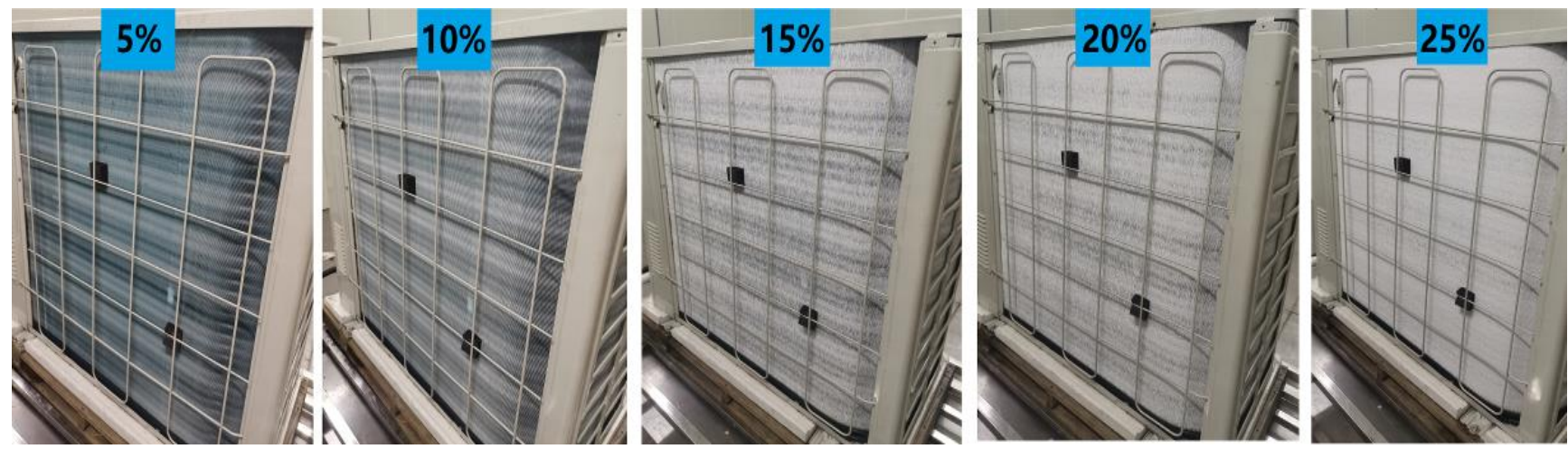

Figure 8. Frost mass picture corresponded to current change rate of condenser fan at $-7^{\circ} \mathrm{C}$ of outdoor temperature.

$-7^{\circ} \mathrm{C}$, the frost mass was changed under different current change rate of condenser fan. When the current change rate was $5 \%$, the frost mass in the condenser was very small. However, when the current change rate was more than $25 \%$, the fins of the condenser were almost all sealed. When the current change rate was $15 \%-20 \%$, the frost mass was moderate. At this time, the defrosting could be started, which could not only avoid defrosting frequently, but also ensure that the ability was not decay too large.

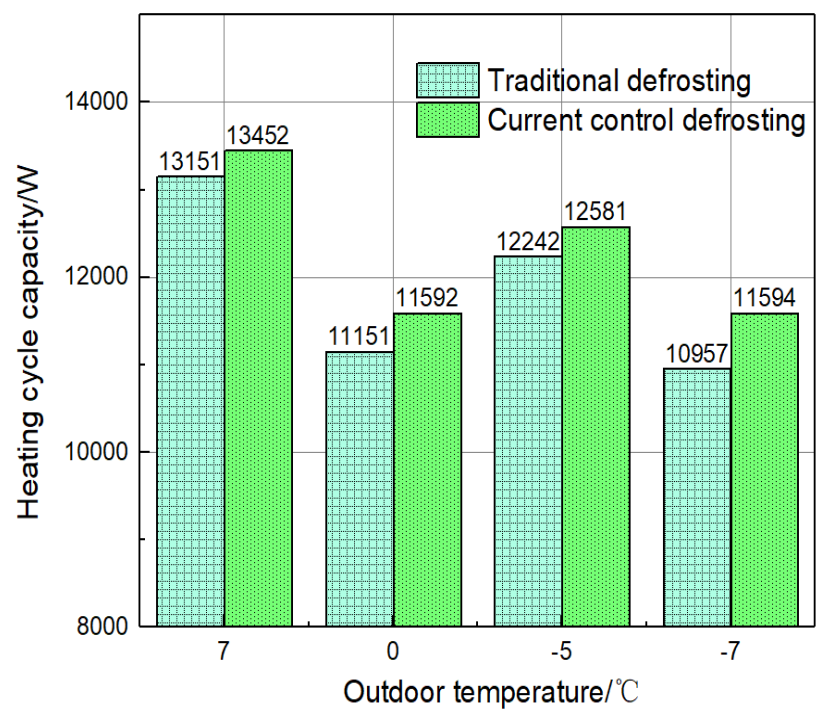

Figure 9. Comparison of heating cycle capacity of two defrosting methods at different outdoor temperature.

\subsection{Comparison between Current Control Defrosting and Traditional Defrosting \\ (1) Increase of Heating Capacity}

As shown in Table 3, the defrosting conditions of traditional defrosting and current control defrosting were compared. For traditional defrosting, the defrosting time was determined through the relationship between pipe temperature and outdoor temperature. The reliability of defrosting was assured by the accumulated operation time. For current control defrosting, the defrosting time was determined through the current change rate (the best current change rate of the system was $17 \%$ ). The reliability of defrosting was also assured by the accumulated operation time, but the setting time could be extended. The experiments were carried out at $7^{\circ} \mathrm{C}, 0^{\circ} \mathrm{C},-5^{\circ} \mathrm{C}$ and $-7^{\circ} \mathrm{C}$ respectively. The results were shown in Figure 9. For the traditional defrosting, the heating cycle capacity at $7^{\circ} \mathrm{C}, 0^{\circ} \mathrm{C}$ ,$-5^{\circ} \mathrm{C}$ and $-7{ }^{\circ} \mathrm{C}$ was $13151 \mathrm{~W}, 11151 \mathrm{~W}, 12242 \mathrm{~W}$ and $10957 \mathrm{~W}$, respectively. For the current control defrosting, under these four conditions, the heating cycle capacity was $13452 \mathrm{~W}, 11592 \mathrm{~W}, 12581 \mathrm{~W}$ and $11594 \mathrm{~W}$ respectively. The periodic heating capacity was increased by $2.3 \%, 4 \%, 2.8 \%$ and $5.8 \%$ respectively. Therefore, it could be seen that the heating cycle capacity of current control defrosting was better than that of traditional defrosting.

\section{(2) High Control Accuracy}

The traditional defrosting was based on defrosting temperature as the control condition of defrosting. If there were some special circumstances, there would be control deviation. For example, the thermosensor fell off, as shown in Figure 10 (a). If the external air conditioning was placed outdoor for a long time, it is easy to fall off, break or reduce the accuracy of the thermosensor. Therefore, the defrosting process would be advanced and delayed, resulting in the system energy efficiency reduction, poor user experience and other adverse effects. Another special case was uneven frost formation in the condenser, as shown in Figure 10 (b). There were two situations that caused the uneven frost: 1 . The system had less refrigerant charge, so the superheat of the condenser was larger. The local temperature of some flow paths was high, so there was no frosting. 2. For areas with heavy rain and humidity in winter, when it rained, the outside of the condenser heat exchanger first contacted with the air and frosted instantly, while the inside of the heat exchanger rarely frosted. Therefore, it caused uneven frost. The defrosting temperature was only the temperature of one branch. If the frost was uneven, the branch where the defrosting temperature was located could not represent the frost condition of each branch. It leaded to the advance and delay of defrosting process.
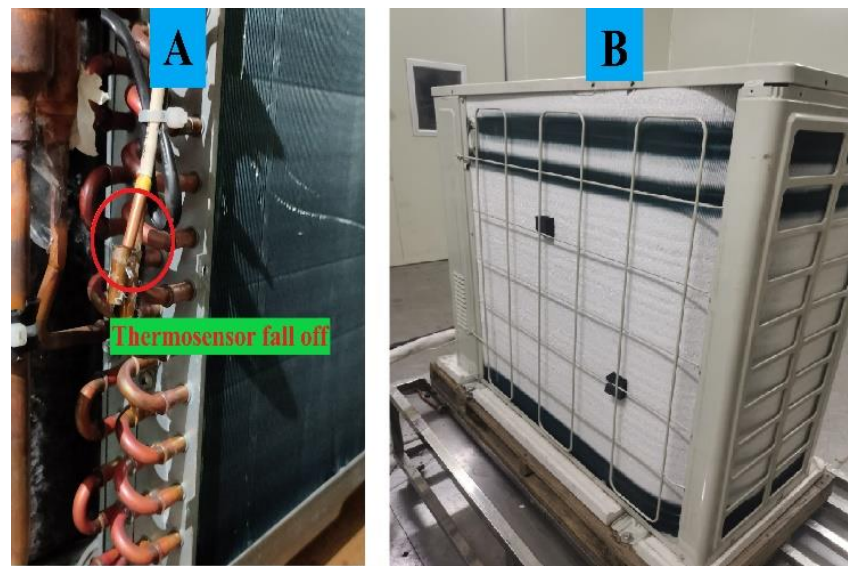

Figure 10. Thermosensor falling off and the uneven frost formation. 
Defrosting condition

$$
\begin{aligned}
& \left\{\begin{array}{c}
T_{a o} \geqslant 0^{\circ} \mathrm{C}: T_{d e f}<T_{a o}-3 \\
-7^{\circ} \mathrm{C} \leqslant T_{a o}<0^{\circ} \mathrm{C}: T_{d e f}<T_{a o}-8 \\
T_{a o}<-7^{\circ} \mathrm{C}: T_{d e f}<T_{a o}-15 \\
T \geqslant 120 \mathrm{~min}
\end{array}\right. \\
& \eta_{I} \geq 17 \% \\
& T \geqslant 300 \mathrm{~min}
\end{aligned}
$$

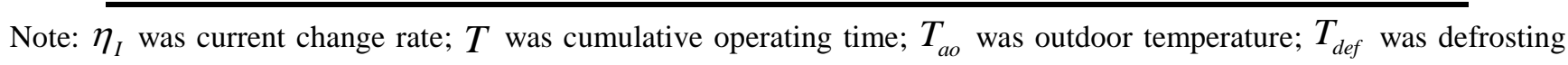

\begin{tabular}{|c|c|c|c|c|}
\hline & \multicolumn{2}{|c|}{ Thermosensor falling off } & \multicolumn{2}{|c|}{ Uneven frost formation } \\
\hline & $\mathrm{CCD}$ & TD & $\mathrm{CCD}$ & TD \\
\hline Operation time & $86 \mathrm{~min}$ & $120 \mathrm{~min}$ & $90 \mathrm{~min}$ & $64 \mathrm{~min}$ \\
\hline Heating cycle capacity & $13479.5 \mathrm{~W}$ & $13002.4 \mathrm{~W}$ & $13401.3 \mathrm{~W}$ & $13376.2 \mathrm{~W}$ \\
\hline Air supply temperature & $32^{\circ} \mathrm{C}$ & $29^{\circ} \mathrm{C}$ & $31^{\circ} \mathrm{C}$ & $35^{\circ} \mathrm{C}$ \\
\hline Capacity decay rate & $15.62 \%$ & $44.7 \%$ & $16.3 \%$ & $10.47 \%$ \\
\hline
\end{tabular}
time.

Table 4. Compared two defrosting methods of performance parameters

Note: Current Control Defrosting (CCD), Traditional Defrosting (TD)

The current control defrosting could solve the above problems. This was because the current value of fan was only related to the resistance after frosting, which directly reflected the frosting condition of condenser. As shown in Table 4, it compared performance parameters of two defrosting methods when the outdoor temperature was $7^{\circ} \mathrm{C}$. It could be seen from the table that whether the thermosensor falling off or the uneven frost formation, the effect on the current control defrosting was very small. The thermosensor falling off had a great influence on the traditional defrosting. The temperature received by the thermosensor was high, which caused the defrosting delay. The system started to defrost when the operation time was 120 minutes. At this time, the heating cycle capacity was $13002.4 \mathrm{~W}$, the air supply temperature was $29^{\circ} \mathrm{C}$, and the capacity decay rate was $44.7 \%$. Both the system energy efficiency and user experience were worse than the current control defrosting. For the uneven frost formation of the condenser, if the path of thermosensor was frosting, the defrosting temperature got low. The defrosting time was 64 minutes ahead of the normal time. At this time, the heating cycle capacity was $13376.2 \mathrm{~W}$, the air supply temperature was $35^{\circ} \mathrm{C}$, and the capacity decay rate was $10.47 \%$. Although the air supply temperature was high and the capacity decay rate was low, the heating cycle capacity was poor due to the frequent defrosting. To sum up, compared with the traditional defrosting, the accuracy of current control defrosting was higher.

\section{Conclusions}

When the indoor temperature was $32^{\circ} \mathrm{C}$, the outdoor dry bulb temperature was $7^{\circ} \mathrm{C}, 0^{\circ} \mathrm{C},-5^{\circ} \mathrm{C}$ and $-7^{\circ} \mathrm{C}$, and the wet bulb temperature was $6^{\circ} \mathrm{C}, 0{ }^{\circ} \mathrm{C},-6^{\circ} \mathrm{C}$ and $-8^{\circ} \mathrm{C}$ respectively. The following conclusions could be drawn:

- When the heating capacity decayed by $15 \%$, the defrosting temperatures corresponding to the four outdoor temperatures were $-3^{\circ} \mathrm{C},-10.6^{\circ} \mathrm{C},-13.7^{\circ} \mathrm{C}$ and $-14.5^{\circ} \mathrm{C}$; the corresponding liquid pipe temperatures were $-10^{\circ} \mathrm{C},-18^{\circ} \mathrm{C},-21.5^{\circ} \mathrm{C}$ and $-22^{\circ} \mathrm{C}$; the defrosting times were $101 \mathrm{~min}, 33 \mathrm{~min}, 74 \mathrm{~min}$ and $73 \mathrm{~min}$ respectively; and the current change rate of condenser fan was about $17 \%$. Compared with other defrosting control method, the current change rate of the condenser fan was taken as the start-up sign of defrosting. The control was simple, and the accurate defrosting could be realized, which was less affected by the change of outdoor temperature.

- For the air conditioning system, the appropriate fan current change rate could be selected as the start-up sign of defrosting through the maximum heating capacity, supply air temperature and capacity decay rate. Under the four working conditions, the current change rate corresponding to the maximum heating cycle capacity was $15 \%$; the heating effect became worse when the air supply temperature was lower than $32{ }^{\circ} \mathrm{C}$, and the current change rate was $15 \%-20 \%$; when the heating capacity decayed by $15 \%$, defrosting shall be carried out in time, and the current change rate was $15 \%-20 \%$. Therefore, it was most reasonable to start defrosting when the current change rate of condenser fan was $15 \%-20 \%$.

- Compared with the traditional defrosting, the heating capacity of the current control defrosting is good. Under the four working conditions, the heating cycle capacity increased by $2.3 \%, 4 \%, 2.8 \%$ and $5.8 \%$ in turn. At the same time, the control accuracy of the current control defrosting is better than the traditional defrosting during the thermosensor falling off and the uneven frost formation.

\section{Acknowledgements:}

It is gratefully acknowledged that this work is sponsored by Key Laboratory of Ningbo AUX Air Conditioning Co., Ltd.

\section{References:}

[1] P. Byrne, J. Miriel, Y. Lenat, "Experimental study of an air-source heat pump for simultaneous heating and cooling - Part 2: Dynamic behaviour and two-phase thermosiphon defrosting technique," Appl. Energy, 88, 3072-3078,

2011. 
[2] M. Wang, R. Q. Zang, E. Hu, A. W. Ezzat, "Investigation of air cooler fan start-up delay in liquid refrigerant defrosting system," Appl. Therm. Eng., 143, 302-307, 2018.

[3] M. L. Qu, L. Xia, S. M. Deng, Y. Q. Jiang, “A study of the reverse cycle defrosting performance on a multicircuit outdoor coil unit in an air source heat pump Part I: Experiments,” Appl. Energy, 91, 122-129, 2012.

[4] K. Laeun, H. Yunho, R. Reinhard, K. Byungsoon, "Field performance measurements of a VRF system with sub-cooler in educational offices for the cooling season," Energy and Buildings, 49, 300-305, 2012.

[5] T. N. Aynur, "Variable refrigerant flow systems: A review," Energy and Buildings, 42, 1106-1112, 2010.

[6] B. Shen, C. K. Rice, "Multiple-zone variable refrigerant flow system modeling and equipment performance mapping," Ashrae Transactions, 118, 420-427, 2012.

[7] P. Parida, F. H. Mei, J. Jiang, W. J. Meng, S. V. Ekkad, "Experimental investigation of cooling performance of metal-based microchannels," Heat Transfer Eng., 31, 485-494, 2010.

[8] S. A. Tassou, D. Datta, D. Marriott, "Frost formation and defrost control parameters for open multideck refrigerated food display cabinets," Proceedings of the Institution of Mechanical Engineers Part A Journal of Power \& Energy, 215, 213-222, 2001.

[9] J. Xiao, W. Wang, Y. H. Zhao, F. R. Zhang, "An analysis of the feasibility and characteristics of photoelectric technique applied in defrost-control," Int. J. Refrig., 32, 1350-1357, 2009.

[10] Z. Y. Wang, H. X. Yang, S. Chen, "Study on the operating performance of cross hot-gas bypass defrosting system for air-to-water screw heat pumps," Appl. Therm. Eng., 59, 398-404, 2013.

[11] K. M. Hwan, L. K. Soo, "Determination method of defrosting start-time based on temperature measurements," Appl. Energy, 146, 263-269, 2015.

[12] W. Wang, J. Xiao, Y. Feng, Q. Guo, L. Wang, "Characteristics of an air source heat pump with novel photoelectric sensors during periodic frost-defrost cycles," Appl. Therm. Eng., 50, 177-186, 2013.
[13] M. J. Song, X. J. Wang, L. Y. Liao, S. M. Deng, "Termination Control Temperature Study for an Air Source Heat Pump Unit During Its Reverse Cycle Defrosting," Energy Procedia, 105, 335-342, 2017.

[14] Y. Q. Jiang, J. K. Dong, M. L. Qu, S. M. Deng, Y. Yao, "A novel defrosting control method based on the degree of refrigerant superheat for air source heat pumps," Int. J. Refrig., 36, 2278-2288, 2013.

[15] H. H. Tan, G. H. Xu, F. T. Tao, X. Q. Sun, W. D. Yao, "Experimental investigation on the defrosting performance of a finned-tube evaporator using intermittent ultrasonic vibration," Appl. Energy, 158, 220-232, 2015.

[16] Y. C. Yoon, H. J. Jeong, K. S. Lee, “Adaptive defrost methods for improving defrosting efficiency of household refrigerator," Energy Conversion \& Management, 157, 511-516, 2018.

[17] J. Allard, R. Heinzen, "Adaptive defrost," IEEE Transactions on Industry Applications, 24, 39-42, 1988.

[18] Y. Hayashi, A. Aoki, S. Adachi, K. Hori, "Study of frost properties correlating with frost formation types," J. Heat Transfer, 99, 239, 1977.

[19] J. H. Zhu, Y. Y. Sun, W. Wang, Y. J. Ge, L. T. Li, J. D. Liu, "A novel Temperature-Humidity-Time defrosting control method based on a frosting map for air-source heat pumps," Intern. J. Refrig., 54, 45-54, 2015.

[20] J. B. Zeng, X. L. Guo, J. H. Huang, "Experimental study on pulse defrosting of variable frequency air conditioner," Refrig. \& air conditioning, 14, 107, 2014.

[21] L. Li, W. F. Jin, H. Li, "Analysis of the influence of air temperature on indoor comfort," Green technology, 2, 274-276, 2014. 